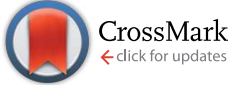

Cite this: RSC Adv., 2015, 5, 107058
Received 14th September 2015 Accepted 3rd December 2015

DOI: $10.1039 / c 5 r a 18783 d$

www.rsc.org/advances

\title{
Voltammetric determination of an antipsychotic agent trifluoperazine at a boron-doped diamond electrode in human urine
}

\begin{abstract}
D. Stanković, ${ }^{a}$ T. Dimitrijević, ${ }^{b}$ D. Kuzmanović, ${ }^{b}$ M. P. Krstićc and B. B. Petković ${ }^{\star d}$
A simple and efficient procedure is described for electrochemical determination of trifluoperazine (TFP), a prominent compound in a large group of phenothiazine derivatives with potent physiological activity. This method is based on the electrochemical oxidation of TFP in Britton-Robinson buffer solution in $\mathrm{pH}$ 6 at a boron-doped diamond electrode. Cyclic voltammetry provided a four well defined oxidation peaks at $+0.65,+0.83,+1.06$ and $+1.35 \mathrm{~V}$ ( vs. Ag/AgCl/3 M KCl electrode). Differential pulse voltammetry was applied as a very sensitive analytical technique for the determination of micromolar amounts of TFP. Two oxidation peaks on higher potentials were chosen for quantification of TFP. Under optimized conditions, the analytical curves obtained were linear in the TFP concentration range of 1.0 to $37.0 \mu \mathrm{mol}$ $\mathrm{L}^{-1}$, with a detection limit of 0.7 and $0.6 \mu \mathrm{mol} \mathrm{L}^{-1}$, respectively. The effect of interfering agents (common urinary compounds) appeared to be negligible confirming the favourable selectivity of the method. The proposed method was analytically applied by determination of trifluoperazine content in model human urine samples with good accuracy (recoveries varied from 97\% to 104\%). The developed approach could be beneficial in analysis of TFP in biological samples using a boron-doped diamond electrode as an up-to-date electrochemical sensor and could represent an inexpensive analytical alternative to separation methods.
\end{abstract}

\section{Introduction}

Trifluoperazine, chemically named as 10-[3-(4-methyl-1-piperazinyl)propyl]-2-(trifluoromethyl)-10H-phenothiazine,

(TFP)

(Scheme 1) is a typical compound of the phenothiazine chemical class. The primary application of trifluoperazine is for treating schizophrenia by acting through minimizing hallucinations, delusions, and disorganized thought and speech. ${ }^{1}$ TFP is also indicated for patients with behavioral problems, severe nausea and vomiting as well as severe anxiety. While its therapeutic action is ascribed to the blockade of presynaptic dopamine D1 and D2 receptors in the mesocortical and mesolimbic pathways, ${ }^{2}$ TFP is also known as a potent calmodulin antagonist, suppressing calmodulin-dependent phosphorylation of several protein components, such as sarcoplasmic reticulum proteins. ${ }^{3,4}$ As the drug is extensively metabolized by the liver and excreted in urine in animals and humans there is a need for a simple and sensitive method for the analysis of these

\footnotetext{
Innovation Center of the Faculty of Chemistry, Department of Analytical Chemistry, University of Belgrade, Belgrade, Serbia

${ }^{b}$ Faculty of Chemistry, University of Belgrade, Belgrade, Serbia

${ }^{c}$ Faculty of Veterinary Medicine, University of Belgrade, Belgrade, Serbia

${ }^{d}$ Faculty of Natural Science and Mathematics, University of Priština, Kosovska Mitrovica, Serbia. E-mail: bedpet@orion.rs; branka.petkovic@pr.ac.rs; Fax: +38128 425 399; Tel: +38128425396
}

compound in biological fluids and pharmaceutical and clinical preparations.

The official methods for the determination of TFP are volumetric nonaqueous titration with perchloric acid (described in United States Pharmacopeia ${ }^{5}$ ), and determination of the end point potentiometrically where unreacted hydrochloric acid was titrated against $\mathrm{NaOH}$ after treating with drugs $\left(\right.$ British Pharmacopeia ${ }^{6}$ ). The reported official methods require a large quantity of drug samples and organic solvents. In order to develop rapid, accurate, applicable, sensitive and more convenient method for determination of TFP in pure and dosage forms, several techniques were<smiles>CN1CCN(CCCN2c3ccccc3Sc3ccc(C(F)(F)F)cc32)CC1</smiles>

Scheme 1 10-[3-(4-Methyl-1-piperazinyl)propyl]-2-(trifluoromethyl)$10 \mathrm{H}$-phenothiazine, (TFP). 
employed. As trifluoperazine is easily oxidized by different chemicals, numerous spectrophotometric methods were used for determination of this compound. ${ }^{7-17}$ Other methods have been reported in this purpose, including fluorimetry, ${ }^{\mathbf{1 8 , 1 9}}$ capillary zone electrophoresis, ${ }^{20}$ high performance liquid chromatography (HPLC) and $\mathbf{1}^{\mathbf{2 1 - 2 4}}$ high-performance thin-layer chromatography (HPTLC). ${ }^{25,26}$

As for electrochemical methods, it was reported that a polyaminobenzene sulphonic acid/single-walled carbon nanotubes composite-modified glassy carbon electrode could effectively accumulate trifluoperazine and generate a sensitive anodic peak at $0.72 \mathrm{~V}$ (versus SCE) in $\mathrm{pH} 6.1$ which was used for quantification by electrochemical impedance method (EIS). ${ }^{27} \mathrm{~A}$ sensitive electroanalytical method for the determination of trifluoperazine has been investigated by adsorptive stripping differential pulse voltammetry on multiwalled carbon nanotube-modified glassy carbon and it was successfully applied to the determination of this compound in pharmaceuticals. ${ }^{28}$ Based on literature search, contrary to chemical oxidation, electrochemical oxidation of TFP is barely researched and used for analytical determination of this compound.

The present investigation aims to develop a simple, rapid, sensitive and cost-effective electrochemical method on unmodified carbon electrode. Some advantages of a borondoped diamond electrode (BDDE) are low and stable background current, extreme electrochemical stability in alkaline and acidic media, excellent long-term response stability and high response sensitivity. ${ }^{29}$ This type of carbon electrode is almost resistant to contamination of surface with various chemical spaces, easy to maintain and has a very wide working potential window ${ }^{30}$ which could provide insight into the electrochemical oxidation of TFP in more positive anodic potentials. By selecting of a voltammetric pulse technique for electrochemical detection, the low detection limit and low background currents could be achieved. ${ }^{31}$ Finally, the practical usefulness of evaluated method should be tested in the assessment of trifluoperazine content in model human urine samples.

\section{Experimental}

\section{Reagents and standards}

All chemicals were of analytical grade and used without further purification. All aqueous solutions were prepared with double distilled, deionized water. Trifluoperazine dihydrochloride $\left(\mathrm{C}_{21} \mathrm{H}_{24} \mathrm{~F}_{3} \mathrm{~N}_{3} \mathrm{~S} \cdot 2 \mathrm{HCl}\right)$ was purchased from sigma. The stock solution $\left(10^{-3} \mathrm{~mol} \mathrm{~L}^{-1}\right)$ was prepared with deionized water and stored at $+4{ }^{\circ} \mathrm{C}$ in darkness. Working solutions were daily prepared by appropriate dilution of the stock solutions. Britton Robinson buffer (B.R. buffer) was made from $40 \mathrm{mM}$ of boric acid, $40 \mathrm{mM}$ of phosphoric acid, and $40 \mathrm{mM}$ of acetic acid and titrated to the desired $\mathrm{pH}$ with $0.2 \mathrm{M}$ sodium hydroxide.

\section{Apparatus and electrochemical measurements}

Cyclic voltammetric (CV) measurements and differential pulse voltammetry (DPV) measurements were performed using an electrochemical system $\mathrm{CH}$ Instruments (USA). The cell $(10 \mathrm{~mL})$ consisted of three-electrode system: a boron-doped diamond electrode (Windsor Scientific Ltd, Slough, Berkshire, United Kingdom) embedded in a polyether ether ketone (PEEK) body with an inner diameter of $3 \mathrm{~mm}$, a resistivity of $0.075 \Omega \mathrm{cm}$ and a boron doping level of $1000 \mathrm{ppm}$ (as declared by the supplier) was used as the working electrode, an $\mathrm{Ag} / \mathrm{AgCl}$ (saturated $\mathrm{KCl}$ ) was the reference electrode and Pt with surface area $180 \mathrm{~mm}^{2}$ was a counter electrode. At the beginning of the work day BDD electrode was anodically pretreated $(+2 \mathrm{~V})$ in $0.5 \mathrm{M}$ sulfuric acid followed by cathodically pretreatment $(-2 \mathrm{~V})$. Both processes were done for $180 \mathrm{~s}$. These processes ensure that electrode surface is gets rid of any contaminants and also renew the hydrogen terminated surface. During the day before the measurements the electrode was slightly polished with piece of cotton. $^{32}$

The cyclic voltammograms of standard TFP solutions were recorded in the potential range from 0.0 to $1.5 \mathrm{~V}$, using a scan rate of $10 \mathrm{mV} \mathrm{s}^{-1}$. To found best experimental conditions for differential pulse voltammetry modulation time was varied from 20 to $80 \mathrm{~ms}$, and pulse amplitude was changed in range of 10 to $90 \mathrm{mV}$. The measurements were performed in unaerated solutions. The $\mathrm{pH}$ measurements were carried out using a Hanna Instruments pH-meter with a Hanna Instruments combined $\mathrm{pH}$ reference electrode. All of the experiments were done at room temperature $\left(25^{\circ} \mathrm{C}\right)$.

\section{Preparation of urine samples}

For the preparation of model human urine samples, a fresh human urine samples was collected from 4 healthy volunteers. The samples were acidified by adding $0.1 \mathrm{~mL}$ of $5 \mathrm{~mol} \mathrm{~L}^{-1}$ hydrochloric acid in $10 \mathrm{~mL}$ of urine. Thereafter, samples were centrifuged at $4000 \mathrm{rpm}$ for $10 \mathrm{~min}$ and the supernatant solutions were taken and stored in the refrigerator. Each $0.1 \mathrm{~mL}$ of urine sample was taken and diluted to $10 \mathrm{~mL}$ with BrittonRobinson buffer at pH 6 and then directly analyzed. Prepared urine samples were spiked with appropriate amount of standard TFP and concentration of TFP and recovery was determined from calibration curve.

\section{Results and discussion}

\section{Cyclic voltammetry of TFP at boron-doped diamond electrode and influence of $\mathbf{p H}$}

Taking into account a structure of the trifluoperazine (Scheme 1) it can be assumed that its electrochemical behavior should define by phenothiazine core and the attached piperazine ligand. Cyclic voltammetric responses of $10^{-5} \mathrm{M}$ TFP solution were obtained at BDDE in B.R. buffer in different $\mathrm{pH}$ values at scan rate of $10 \mathrm{mV} \mathrm{s}^{-1}$ (Fig. 1). At a lower $\mathrm{pH}$ values, a four wellformed oxidation peaks and one reduction peak were observed for TFP within the potential window from 0.0 to $1.5 \mathrm{~V}$.

The oxidation mechanism of phenothiazine and its derivates is well known. ${ }^{33}$ The cyclic voltammogram indicates that peak $\mathrm{Ox}_{\mathrm{I}}$ and peak $\mathrm{Rd}$ form an almost reversible couple on $\mathrm{pH}$ lower than 5, above that values this reverse peak despaired. At the 
(a)

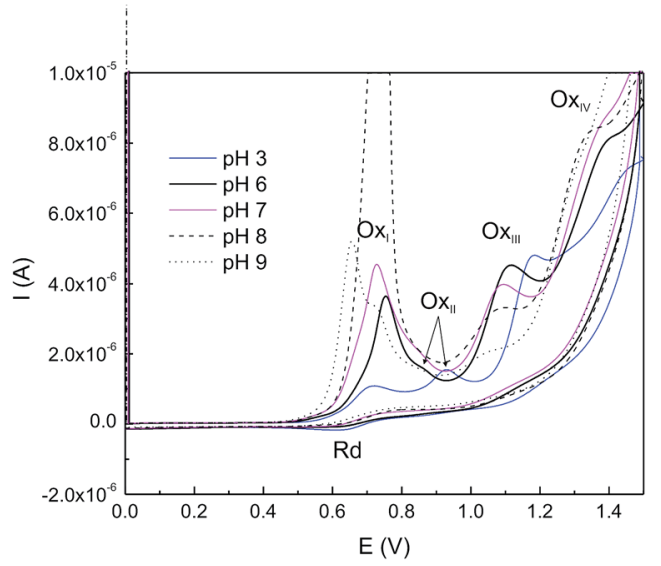

(b)

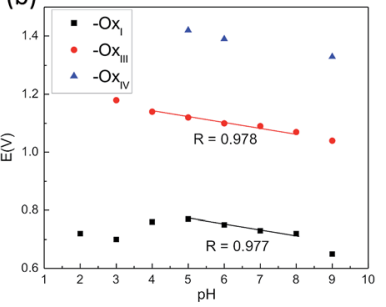

(c)

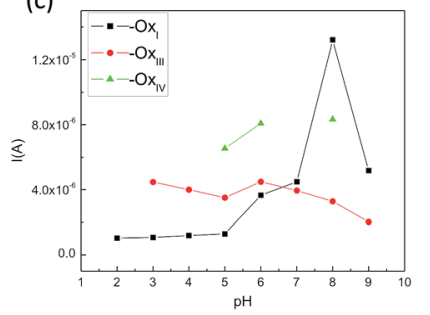

Fig. 1 Cyclic voltammetric profiles of $10^{-5} \mathrm{M}$ TFP in different pH B.R. buffer solutions at BDDE, scan rate of $10 \mathrm{mV} \mathrm{s}^{-1}$ (a); the influence of the $\mathrm{pH}$ on peak potential (b) and peak current (c)

same time, in acidic media $\mathrm{Ox}_{\mathrm{II}}$ is shifted to less positive values with increasing of $\mathrm{pH}$ and peaks $\mathrm{Ox}_{\mathrm{I}}$ and $\mathrm{Ox}_{\mathrm{II}}$ are merge into single peak on $\mathrm{pH}$ higher than 6 . The origin of peak $\mathrm{Ox}_{\mathrm{I}}$ is attributed to one electron electrochemical oxidation of TFP to a cation radical which is quite reactive and rapidly disappears. The further peak, $\mathrm{Ox}_{\mathrm{II}}$ is derived of one electron electrooxidation of cation radical to a dication which hydrolyzes to sulfoxide. These two electrons might be lost together in one step and produce only one anodic peak, which depends on used supported electrolyte and $\mathrm{pH}$. Kinetic of the cation radical decay reaction appear to strongly depend on nucleophile species from used buffer solutions. ${ }^{28,33}$

Taking into account that TFP contains a tertiary amine in its molecular structure, this is a basic center with the availability of non-bonding electron as donor. So, it can be assumed that the

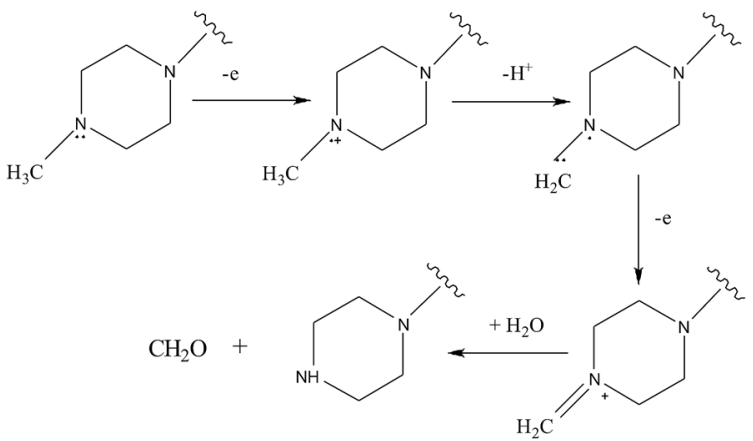

Scheme 2 Electrochemical oxidation mechanism of piperazine group in TFP. next oxidation steps of TFP should be located on the piperazine ring $^{34,35}$ and the peaks $\mathrm{Ox}_{\mathrm{III}}$ and $\mathrm{Ox}_{\mathrm{IV}}$ should be attributed to next electrochemical reactions: according to the literature, ${ }^{36,37}$ a nitrogen on the piperazine ring loses an electron to form a cation radical and this cation radical loses a proton and an electron in subsequent steps to form a quaternary Schiff base. Thus quaternary Schiff base was rapidly hydrolysed to the secondary amine and formaldehyde. The mechanism is shown in Scheme 2.

The influence of $\mathrm{pH}$ was studied in the $\mathrm{pH}$ range from 2-9 in a solution containing $10^{-5} \mathrm{M}$ TFP in appropriate B.R. buffer solutions. Only selected CV profiles are presented for clarity in Fig. 1a, while dependence of peak potential and peak current $v s$. $\mathrm{pH}$ (all $\mathrm{pH}$ values in studied $\mathrm{pH}$ range) were given in graphs (b) and (c). As is seen in Fig. 1, there is a strong influence of $\mathrm{pH}$ on peak potential and peak current, especially for oxidation peaks originating from phenothiazine core of TFP. Acidic media also favors a two-step oxidation of phenotiazine but the second oxidation peak $\left(\mathrm{Ox}_{\mathrm{II}}\right)$ was not well defined, or disappeared in some profiles. The peak $\mathrm{Ox}_{\mathrm{I}}$ was surprisingly high at $\mathrm{pH} 8$, but the peak current is very sensitive to small changes in $\mathrm{pH}$ value. Peaks originating from piperazine in TFP molecule were much less sensitive to $\mathrm{pH}$ change. $\mathrm{Ox}_{\mathrm{IV}}$ could not be noticed on $\mathrm{pH} 9$ which is in accordance with previously reported observation that two oxidation peaks clearly merged into a single peak. ${ }^{35} \mathrm{~A}$ negative shift in anodic peaks has occurred by increasing $\mathrm{pH}$. This confirms that $\mathrm{H}^{+}$participates in the oxidation of trifluoperazine. The pH 6 represents the most suitable value of B.R. buffer solution for determination of TFP at BBDE due to maximal or almost maximal value of peak current for all oxidation peaks. On this $\mathrm{pH}$ value, electrooxidation process is the most resistant to slight changes in $\mathrm{pH}$.

\section{Effect of potential scan rate}

The effect of the scan rate $(\nu)$ on the peak current was investigated in order to characterize the mass transport in diffusion layer during oxidation reaction. Cyclic voltammograms of $10^{-5}$ M TFP in B.R. buffer solution at pH 6 on BDDE were recorded at different potential sweep rates and the graph of peak current for all peaks as function of the square root of potential scan rate was shown on Fig. 2. It is evident from Fig. 2 that the peak current of TFP linearly increased with the square root of the scan rate within the range of $10-300 \mathrm{mV} \mathrm{s}^{-1}$, for all oxidation peaks and one reduction peak. Hence, the electrode reaction is controlled by diffusion as a rate-determining step and the adsorption and/or other specific interactions on self-assembled BDD electrode surface are negligible.

The oxidation peak potential of $\mathrm{Ox}_{\mathrm{II}}$ is mildly shifted towards more positive values as the scan rate increased which is characteristic for irreversible electrochemical reactions. ${ }^{38}$

\section{Differential pulse voltammetry of TFP and analytical measurements}

Differential pulse voltammetry (DPV) at BDDE was applied as a highly sensitive and rapid electrochemical method for the detection of trace amounts of trifluoperazine. Working 


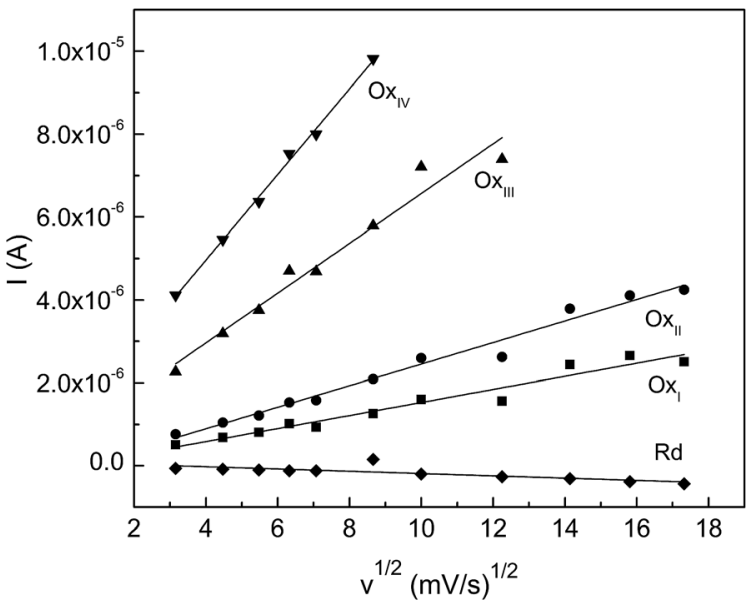

Fig. 2 The peak current as function of $\nu^{1 / 2}$ derived from cyclic voltammograms of $10^{-5} \mathrm{M}$ TFP for various scan rates $(\nu)\left(10-300 \mathrm{mV} \mathrm{s}^{-1}\right)$ in B.R. buffer solution at $\mathrm{pH} 6$ on BDD electrode.

conditions were studied by variation of modulation time and modulation amplitude in order to provide lowest detection limit. The optimization was carried out in previously selected B.R. buffer solution at pH 6 and concentration of TFP was 20 $\mu \mathrm{M}$. During one parameter was varied others were kept fixed. After variation of modulation time from 20 to $80 \mathrm{~ms}$, and changing pulse amplitude in range of 10 to $90 \mathrm{mV}$, the optimal modulation time of $40 \mathrm{~ms}$ and pulse amplitude of $50 \mathrm{mV}$ were chosen taking into account the distortion and height of the oxidation peaks and other experiments were carried out under these optimized parameters.

Fig. 3 (top graph) exhibits DPVs for buffered solutions of TFP ( $\mathrm{pH}$ is 6.0) at BDDE. The anodic peaks $\left(\mathrm{Ox}_{\mathrm{I}}, \mathrm{Ox}_{\mathrm{II}}, \mathrm{Ox}_{\mathrm{III}}, \mathrm{Ox}_{\mathrm{IV}}\right)$
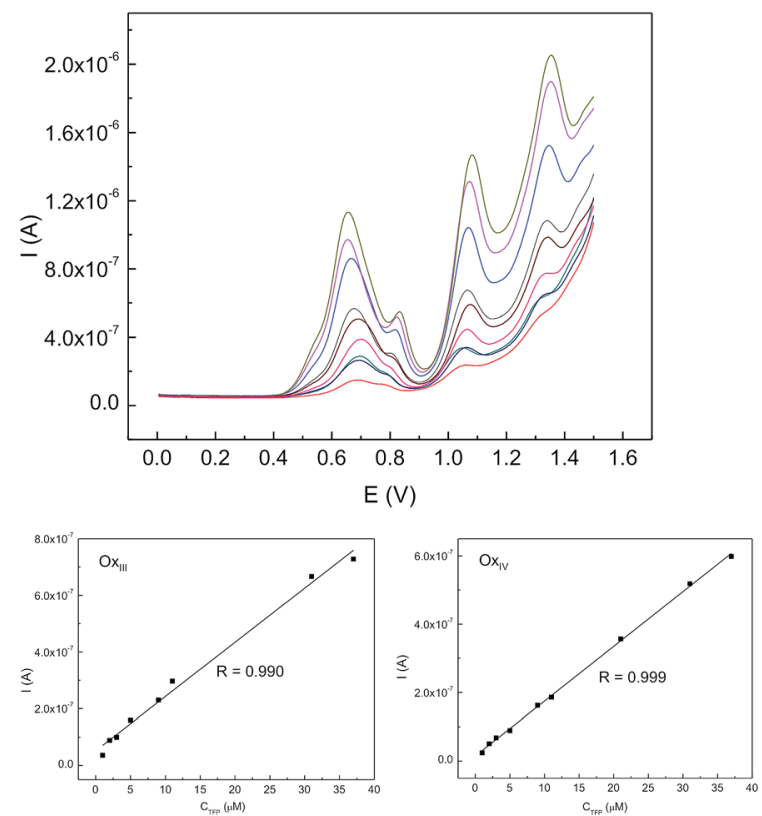

Fig. 3 DPV of BDDE with TFP added in concentration of $1.0 \times 10^{-6}$ to $3.7 \times 10^{-5} \mathrm{~mol} \mathrm{~L}^{-1}, \mathrm{pH}=6$ (top); calibration curves for TFP (bottom). appeared at potentials of $0.65,0.83,1.06$ and $1.35 \mathrm{~V}$, respectively. Anodic peak $\mathrm{Ox}_{\mathrm{II}}$ is not well defined, while $\mathrm{Ox}_{\mathrm{I}}$ is usually used for quantification of almost all phenothiazines. ${ }^{33,39-41}$ Hence, the third and forth anodic peaks originated from piperazine ring $\left(\mathrm{Ox}_{\mathrm{III}}, \mathrm{Ox}_{\mathrm{IV}}\right)$ were chosen for TFP determination. Furthermore, the impact of possible interferences is reduced on such relatively high potential. Those two peaks were reproducible and show linear dependence on current density $v s$. the concentration of TFP. The calibration curves were constructed by plotting the current density $\mathrm{Ox}_{\mathrm{III}}$ and $\mathrm{Ox}_{\mathrm{IV}} v s$. the concentration of TFP. A dynamic linear range of this method was in concentration range from $1.0 \times 10^{-6}$ to $3.7 \times 10^{-5} \mathrm{~mol} \mathrm{~L}^{-1}$ with obtained detection limits of $7 \times 10^{-7}$ for $\mathrm{Ox}_{\mathrm{III}}$ and $6 \times 10^{-7} \mathrm{~mol}$ $\mathrm{L}^{-1}$ for $\mathrm{Ox}_{\mathrm{IV}}$. Detection limits were estimated from three times the standard deviation. The obtained detection limits of this unmodified electrode are comparable with anthers (modified electrodes) reported in the literature for TFP or structurally similar compounds (thioridazine hydrochloride determination at N-CNTs/gold-modified electrode with detection limit of 1.3 $\mu \mathrm{M},{ }^{41}$ a poly-ABSA/SWNTs composite-modified electrode used for TFP determination with LOD of $1 \mathrm{nM},{ }^{27}$ NiAlPO-5 modified carbon paste electrode for determination of thioridazine with LOD of $\left.9 \times 10^{-8} \mathbf{M}^{40}\right)$. Composite syntheses or electropolymerization were required for preparation of those modified electrodes, contrary to simple cleaning and preparation process used for unmodified BDDE in this work.

The resulting calibration plots for both oxidation peaks (Fig. 3, bottom graphics) are followed by equations:

$$
\begin{aligned}
& \mathrm{Ox}_{\mathrm{III}}: I_{\mathrm{p}}(\mathrm{A})=1.91 \times 10^{-8} \times C_{\mathrm{TFP}}+5.19 \times 10^{-8} ; R=0.990 \\
& \mathrm{Ox}_{\mathrm{VI}}: I_{\mathrm{p}}(\mathrm{A})=1.49 \times 10^{-8} \times C_{\mathrm{TFP}}+1.60 \times 10^{-8} ; R=0.999
\end{aligned}
$$

The repeatability of method was evaluated by six replicate DPV measurements at the $7 \times 10^{-6}$ and $15 \times 10^{-6} \mathrm{M}$ TFP concentration under the same operating conditions. The peak current of $\mathrm{Ox}_{\mathrm{III}}$ and $\mathrm{Ox}_{\mathrm{IV}}$ were 3.8 and $6.2 \%$ for lower concentration and 5.43 and $2.94 \%$ for higher concentration of TFP. The

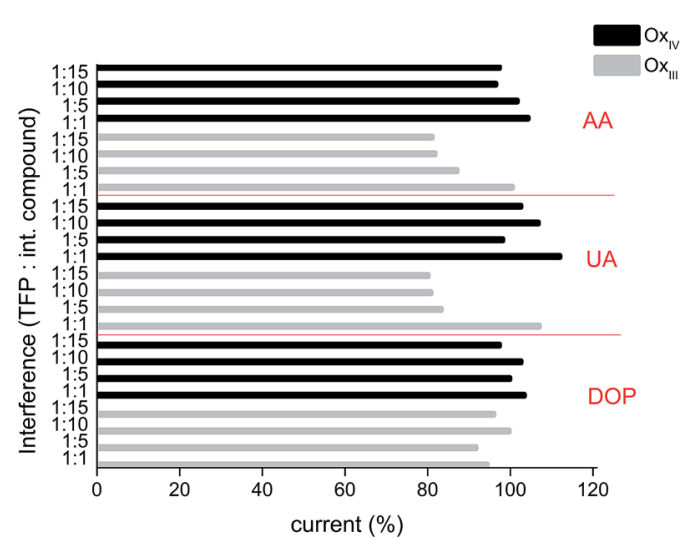

Fig. 4 The influence of the interfering compounds on current obtained for determination of TFP under optimized experimental conditions. 
Table 1 Recovery data observed for spiked human urine samples

\begin{tabular}{|c|c|c|c|c|c|c|c|}
\hline Sample & $\begin{array}{l}\text { Detected } \\
\left(\times 10^{-6} \mathrm{M}\right)\end{array}$ & \multicolumn{3}{|l|}{ Addition 1} & \multicolumn{3}{|l|}{ Addition 2} \\
\hline 1 & 0.00 & 3.00 & 2.97 & 99.0 & 7.00 & 6.79 & 97.0 \\
\hline 2 & 0.00 & 3.00 & 3.09 & 103.0 & 7.00 & 7.07 & 101.0 \\
\hline 3 & 0.00 & 3.00 & 3.12 & 104.0 & 7.00 & 7.28 & 104.0 \\
\hline
\end{tabular}

RSD value suggests good repeatability of proposed method and confirmed the low adsorption on BDDE during analysis.

\section{Interference study and determination TFP in urine samples}

Nowadays the most of methodologies for drugs determination are based on chromatographic techniques and univariate calibration determination. Although these methodologies are well established, they can present some disadvantages. They usually require time-consuming sample preparation and expensive equipment. Electrochemical methods have proved to be excellent alternatives for the determination of various electroactive drugs. Sample preparation is usually short and in many cases determination is achieved without sample preparation.

Before testing practical applicability of a proposed method in model urine samples, the interfering effect of some ordinary urine compounds was studied. Uric acid (UA), ascorbic acid (AA) and bioactive compound dopamine (DOP) were added in different ratios to TFP in order to determine the influence on current of $\mathrm{Ox}_{\mathrm{III}}$ and $\mathrm{Ox}_{\mathrm{IV}}$ (Fig. 4). Current of solution with TFP before mixing with possible interfering compounds was used as $100 \%$ in calculation. Studied compounds are electroactive in less positive potential region. It is evidently shown that the effect of interfering compound is lower for $\mathrm{Ox}_{\mathrm{IV}}$ and in all cases is lower than $5 \%$.

Urine samples are acidified for preservation and test samples were prepared according the procedure given in section about urine sample preparation. The concentrations of the TFP were determined from the calibration curve (Fig. 3b) by using plot for peak $\mathrm{Ox}_{\mathrm{IV}}$. Results obtained for the determination of the TFP in spiked urine samples and recovery values are listed in Table 1. From this table it can be concluded that proposed method have satisfactory accuracy with minimum matrix effect (advantages of BDD electrode and high oxidation potential of TFP) and could be suitable for quantification of tested compound in real samples. The TFP concentrations which represents detection limits of this method $\left(7 \times 10^{-7}\right.$ and $6 \times 10^{-7} \mathrm{~mol} \mathrm{~L}^{-1}$ for two peaks originated from piperazine ring) correspond to TFP concentration which can be found in urine of patients who used higher therapeutic doses. ${ }^{42}$ Lower concentrations of TFP can be determined using the standard addition method. From recovery results it can be concluded that proposed method possess satisfactory recovery after addition of standard TFP solution, indicating low effect of the tasted solution matrix, and implies that our procedure by employing standard addition method could determine lower concentration of the tested compound.

\section{Conclusions}

Differential pulse voltammetry on boron-doped diamante electrode in Britton-Robinson buffer solution at $\mathrm{pH} 6$ was found to be applicable for determination of a prominent antipsychotic drug trifluoperazine in human urine samples. The simple proposed procedure, without any electrode surface modification, no sample pretreatment steps and a short time analysis represents a valuable electrochemical alternative to the previous approaches. For quantification of TFP, the current peaks originated from piperazine ring are chosen due to selectivity over possible interfering common urinary compounds. The method possesses the necessary sensitivity and reputability of analysis. Obtained detection limits of TFP were $7 \times 10^{-7}$ and $6 \times 10^{-7}$ mol L ${ }^{-1}$ respectively to chosen oxidation peaks. The developed procedure has potential for use in analyzing of other biological fluids and pharmaceutical formulations, therefore, it may represent powerful alternative, in determination of compounds from similar groups, to other more complicated and expensive methods.

\section{Acknowledgements}

Financial support for this study was granted by the Ministry of Educations, Science and Technological Development of the Republic of Serbia (Project Number 45022).

\section{Notes and references}

1 K. H. Ahmed, T. S. Ameen, B. A. Saad and M. Suad, Anal. Sci., 2009, 25, 1295.

2 P. Seeman, Pharmacol. Rev., 1980, 32, 229.

3 M. Chiesi and E. Carafoli, J. Biol. Chem., 1982, 257, 984.

4 K. P. Campbell and D. H. MacLennan, J. Biol. Chem., 1982, 257, 1238.

5 The United States Pharmacopoeia XXIV Revision, The National Formulary XIX Rockville, USP Convention, 2007.

6 British Pharmacopoeia, The Stationary Office London, 2009.

7 A. Tehseen, K. A. Ahmad, N. S. Rabia, M. Jawwad and A. G. Syed, Proc. Pak. Acad. Sci., 2003, 40, 91. 
8 G. Phillip and B. C. Satyanarayana, Indian J. Pharm. Sci., 1978, 40, 153.

9 A. T. Gowda, Indian J. Pharm. Sci., 1984, 46, 220.

10 A. El-Gindy, B. El-Zeany, T. Awad and M. M. Shabana, J. Pharm. Biomed. Anal., 2002, 27, 9.

11 B. Laassis, M. Maafi, J. J. Aaron and M. C. Mahedero, Anal. Lett., 1997, 30, 1541.

12 M. C. Sharma and S. Sharma, World J. Chem., 2011, 6, 80.

13 H. R. Chaudhary, B. Ramesh, B. M. Chetan and L. S. Patil, Int. J. Pharm. Appl., 2010, 1, 76.

14 S. S. Abbas, E. H. Zaazaa, M. Abdelkawy and M. M. Abdelrahman, Drug Test. Anal., 2010, 2, 168.

15 R. B. Saudagar, S. Saraf and S. Saraf, Indian J. Pharm. Sci., 2007, 69, 149.

16 A. El-Gindy, B. El-Zeany, T. Awad and M. M. Shabana, J. Pharm. Biomed. Anal., 2001, 26, 203.

17 K. N. Prashanth, N. Swamy and K. Basavaiah, J. Appl. Spectrosc., 2014, 81, 893.

18 B. Laassis, M. Maafi, J. J. Aaron and M. C. Mahedero, Anal. Lett., 1997, 30, 1541.

19 T. Perez-Ruiz, C. Martinez-Lozano, V. Tomas, D. E. Sidrach and C. Cardona, Talanta, 1993, 40, 1361.

20 E. M. Abdel-Moety and A. O. Al-Deeb, Eur. J. Pharm. Sci., 1997, 5, 1.

21 E. M. Abdel-Moety, A. K. Al-Rashood, A. Rauf and N. A. Khattab, J. Pharm. Biomed. Anal., 1996, 14, 1639.

22 M. Charde, I. Sheikh, S. Dhole and A. V. Kasture, J. Pharma Res., 2010, 3, 1616.

23 S. M. Desai, J. M. Khatri and K. Lalla, Indian Drugs, 1990, 27, 389.

24 S. K. Patel and N. J. Patel, Indian J. Pharm. Sci., 2009, 71, 545.

25 A. Maslanka and J. Krzek, J. AOAC Int., 2005, 88, 70.
26 A. El-Gindy, B. El-Zeany, T. Awad and M. M. Shabana, J. Pharm. Biomed. Anal., 2002, 27, 9.

27 G. Jin, F. Huang, W. Li, S. Yu, S. Zhang and J. Kong, Talanta, 2008, 74, 815.

28 B. Dogan-Topal, J. Solid State Electrochem., 2013, 17, 1059.

29 Ľ. Švorc, D. M. Stanković and K. Kalcher, Diamond Relat. Mater., 2014, 42, 1.

30 Ľ. Švorc, M. Rievaj and D. Bustin, Sens. Actuators, B, 2013, 181, 294.

31 J. Wang and B. A. Freiha, Talanta, 1983, 30, 837.

32 L. Švorc, K. Cinková, J. Sochr, M. Vojs, P. Michniak and M. Marton, J. Electroanal. Chem., 2014, 728, 86.

33 P. Horsman, B. E. Conway and E. Yeager, Comprehensive Treatise of Electrochemistry: Volume 10, Bioelectrochemistry, Plenium Press, New York, 1985.

34 J. M. Kauffmann, J. C. Vire and G. J. Patriarche, Electrochim. Acta, 1987, 32, 1159.

35 B. Uslu, B. Dogan, S. A. Özkan and H. Y. Aboul-Enein, Anal. Chim. Acta, 2005, 552, 127.

36 O. M. Popa and V. C. Diculescu, Electrochim. Acta, 2013, 112, 486.

37 R. N. Hegde, R. R. Hosamani and S. T. Nandibewoor, Colloids Surf., B, 2009, 72, 259.

38 Ľ. Švorc, J. Sochr, J. Svítková, M. Rievaj and D. Bustin, Electrochim. Acta, 2013, 87, 503.

39 K. Madej and P. Kòscielniak, Crit. Rev. Anal. Chem., 2008, 38, 50.

40 M. Amiri, S. Sohrabnezhad and A. Rahimi, Mater. Sci. Eng., C, 2014, 37, 342.

41 X. Feng, C. Wang, R. Cui, X. Yang and W. Hou, J. Solid State Electrochem., 2012, 16, 2691.

42 B. Laassis and J. J. Aaron, Analusis, 1997, 25, 183. 